Journal of Al Azhar University Engineering Sector

Vol. 11, No. 41, October, 2016, 1311-1320

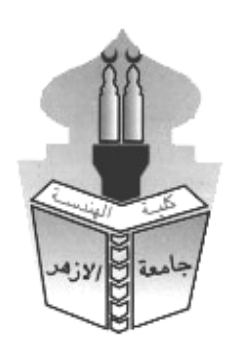

\title{
IMPLEMENTATION OF SELF-TUNING FUZZY PID CONTROL APPLIED ON BRUSHLESS DC MOTOR
}

\author{
Aml Eid ${ }^{1}$, Mohamed A. Shamseldin ${ }^{2}$, R.R. Darwish ${ }^{3}$, W. M. Refaey ${ }^{3}$ \\ and A. M. Abdel Ghany ${ }^{3}$ \\ ${ }^{1}$ High institute of Engineering CSC - 6 October, \\ ${ }^{2}$ Future University in Egypt, \\ ${ }^{3}$ Helwan University, Faculty Of Engineering
}

\begin{abstract}
this paper presents simple implementation for two different control techniques applied on brushless DC motor. The first technique is the conventional PID control while the second technique is the self-tuning fuzzy PID control. In the second technique the main role of fuzzy logic control adjusts the PID control output according to error and change of error. The Arduino microcontroller is used to send the control signal to real system and receive the speed feedback signal. The experimental results show that the superiority for self-tuning fuzzy PID control compared to conventional PID control.
\end{abstract}

\section{KEYWORDS : Brushless DC (BLDC) Motor; Fuzzy Logic Control; PID Control.}

\section{INTRODUCTION}

The brushless DC motor has been widely used in several applications such as, industrial automation, robotics, steel rolling mills, medical, electric traction, aviation, road vehicles, aircraft, military equipment, hard disk, etc. It has high reliability, good efficiency, high power density, low maintenance requirements, lower weight and wide speed range [1]. Moreover, the ratio of torque delivered to the size of the motor is higher, making it useful in applications where space and weight are critical factors [2],[3].

The control technique for a BLDC motor plays a very vital role in enhancing its performance for applications relating to load variations or in positioning applications. This has resulted in an increased interest in intelligent and adaptive controllers [4],[5].

The proportional-integral-derivative (PID) controller is commonly used in several of control and industrial applications due to its simplicity and effectiveness. Though the use of PID control has been a long history in the area of control engineering, the three controller gain parameters, proportional gain $\mathrm{K}_{\mathrm{p}}$, integral gain $\mathrm{K}_{\mathrm{i}}$, and derivative gain $\mathrm{K}_{\mathrm{d}}$, are usually fixed. The drawback of PID controller is poor capability of dealing with system uncertainty, parameter variations and external disturbance [6].

In the last years, there has been extensive interest in self-tuning these three controller parameters. For examples, self-tuning fuzzy PID control method is a good alternative method of controlling, to the complex and unclear model systems, it can achieve simple and effective control, good dynamic response, rising time, overstrike characteristics [7].

Fuzzy logic control (FLC) is a typical intelligent control technique which has been extensively used in several of fields, such as steel making, chemical industry, household appliances and social sciences [8]. The biggest feature of FLC is it can deduce empirical knowledge of the experts by inference rules. It does not require the mathematical model of the controlled object. What's more, it is not sensitive to parameters changing and it has strong 
robustness [9]. In summary, FLC is very suitable for the controlled object with characteristics of large delay, large inertia, non-linear and time-variant [8].

Also, the advantages of FLC are simplicity of control, low cost and flexibility. It is appropriate for speed control applications. The structure of FLC involves three major components, namely, fuzzifier which is used for measurement of the input or definition of the fuzzy sets that will be applied; fuzzy control unit or rule base which provides the system with the necessary decision-making logic based on the rule that determines the control policy; and defuzzifier which combines the actions that have been decided and produces single non fuzzy output that is the control signal of the systems[10].

Real Time Implementation of digital signal processing (DSP) based Fuzzy Logic Controller for Speed Control of BLDC Motor has been presented in [11]. Comparison of Fuzzy PID Controller with Conventional PID Controller in Controlling the Speed of a Brushless DC Motor has been demonstrated in [7].

In this paper a self-tuning fuzzy PID control is introduced in speed regulation system of BLDC motor. The PID controller output can be adjusted real time under self-tuning fuzzy PID control according to error and change of error.

The rest of this paper is organized as follows: the mathematical model of the BLDC motor introduced in Section II. In section III, self-tuning fuzzy PID control is designed for BLDC speed control. In section VI, the experimental results performed on BLDC motor are presented and describes the laboratory setup. The conclusions are given in section $\mathrm{V}$.

\section{DYNAMIC MODEL OF BLDC MOTOR}

The transfer function based mathematical models are commonly used in automatic control fields. Some control design and analysis methods, such as the root-locus method and the frequency response method are also developed based on the system transfer function [12].

Fig.1 illustrates the three-phase BLDC motor is controlled by the full-bridge driving in the two- phase conduction mode [1].

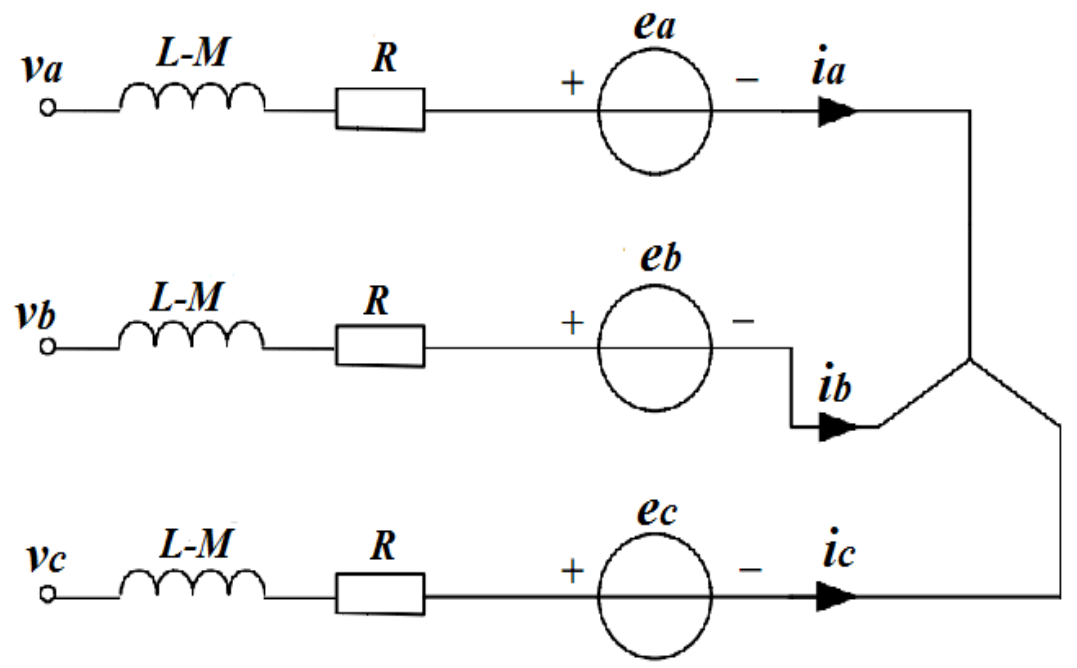

Fig. 1. Equivalent circuit of the BLDC motor.

The transfer function of the BLDC motor at no load may be written as follows:

$$
\begin{gathered}
\frac{\omega(S)}{U_{d}(S)}=\frac{\frac{1}{K_{s}}}{\left(t_{m} \cdot t_{e}\right) \cdot S^{2}+t_{m} \cdot S+1} \\
t_{m}=\frac{3 R J}{K_{\varepsilon} K_{t}} \\
t e=\frac{L}{3 R}
\end{gathered}
$$

Where: 
$U_{d}$ : DC bus voltage.

$t_{m}:$ mechanical time constant.

$t_{e}$ :Electrical constant.

$R$ : Terminal resistance phase to phase.

$L$ : Terminal inductance phase to phase.

$J$ : Rotor moment of inertia.

$\omega$ : Rotor speed.

$K_{e}$ : Coefficient of phase back-EMF constant.

$K_{t}$ : Coefficient of phase torque constant

The block diagram of the drive system is shown in Fig 2. The main components of drive system of BLDC motor consists of six step voltage source inverter, logic circuit, and three hall effect sensors [13].

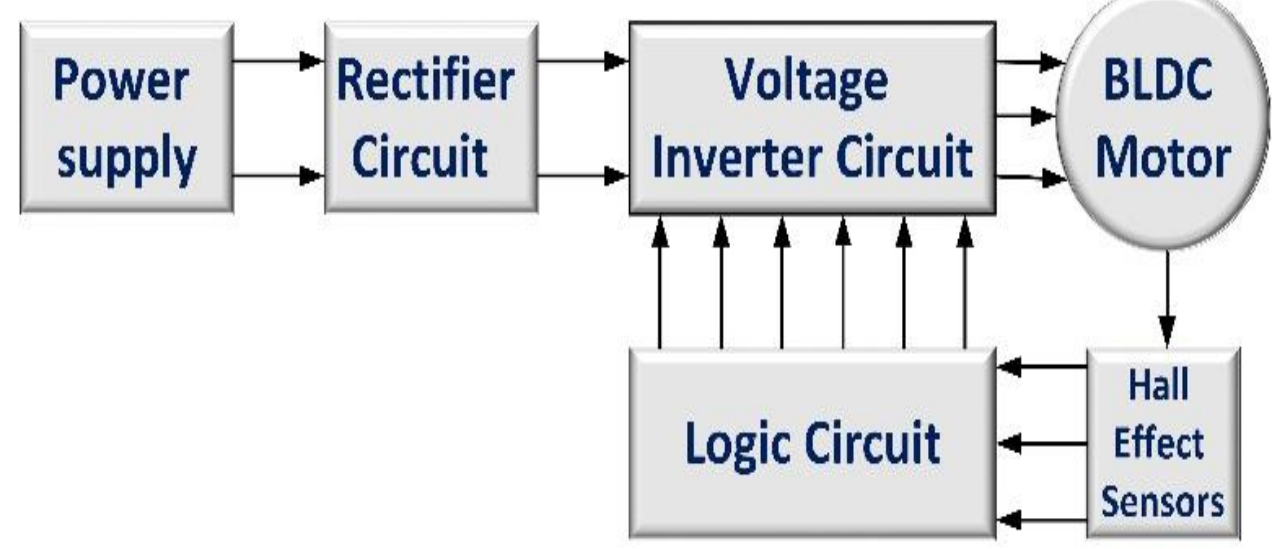

Fig. 2. Brushless DC motor drive system.

Fig. 3 demonstrates the open loop response of BLDC motor drive system. The rated voltage $(24 \mathrm{~V})$ is applied on motor to reach the rated speed (8700 RPM). It can be noted that small speed oscillation due to system nonlinearity and noise.

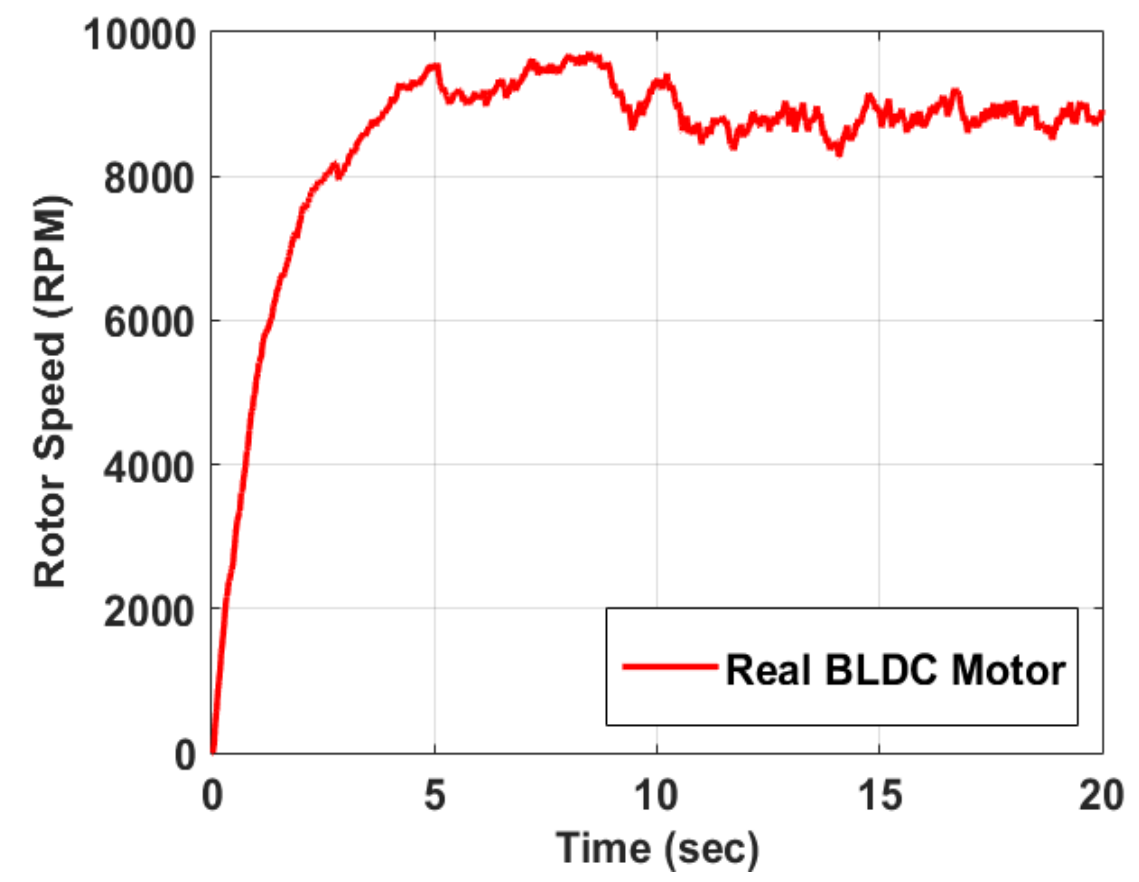

Fig. 3. Open loop response of BLDC motor drive system model. 


\section{SELF-TUNING FUZZY PID CONTROL}

The transfer function of the PID controller is $K(s)=K_{p}+\frac{K_{i}}{i}+K_{d} s$. Where $K_{p}, K_{i}, k_{d}$ are proportional, integral and differential gains respectively. The fůnction of each part of a PID controller can be defined as follows, the proportional part decreases the error responses of the system to disturbances, the integral part eliminates the steady-state error, and finally the derivative part dampens the dynamic response and improves the system stability. The challenge in the PID controller is to choose the three parameters to be appropriate for the controlled plant [14]. There are several methods to define the parameters of PIDcontroller such as try and error and Ziegler-Nichols methods but most of these methods are rough roads. In this, paper the parameters of PID controller obtained by Ziegler-Nichols method as shown in table I.

Table I: Pid Controller Parametrs

\begin{tabular}{|c|c|c|c|}
\hline Parameters & $\mathrm{K}_{\mathrm{p}}$ & $\mathrm{K}_{\mathrm{i}}$ & $\mathrm{K}_{\mathrm{d}}$ \\
\hline PID control & 0.03 & 0.042 & 0.0001 \\
\hline
\end{tabular}

The PID controller output will be tuned using the fuzzy logic control according to error and change of error as shown in Fig. 4.

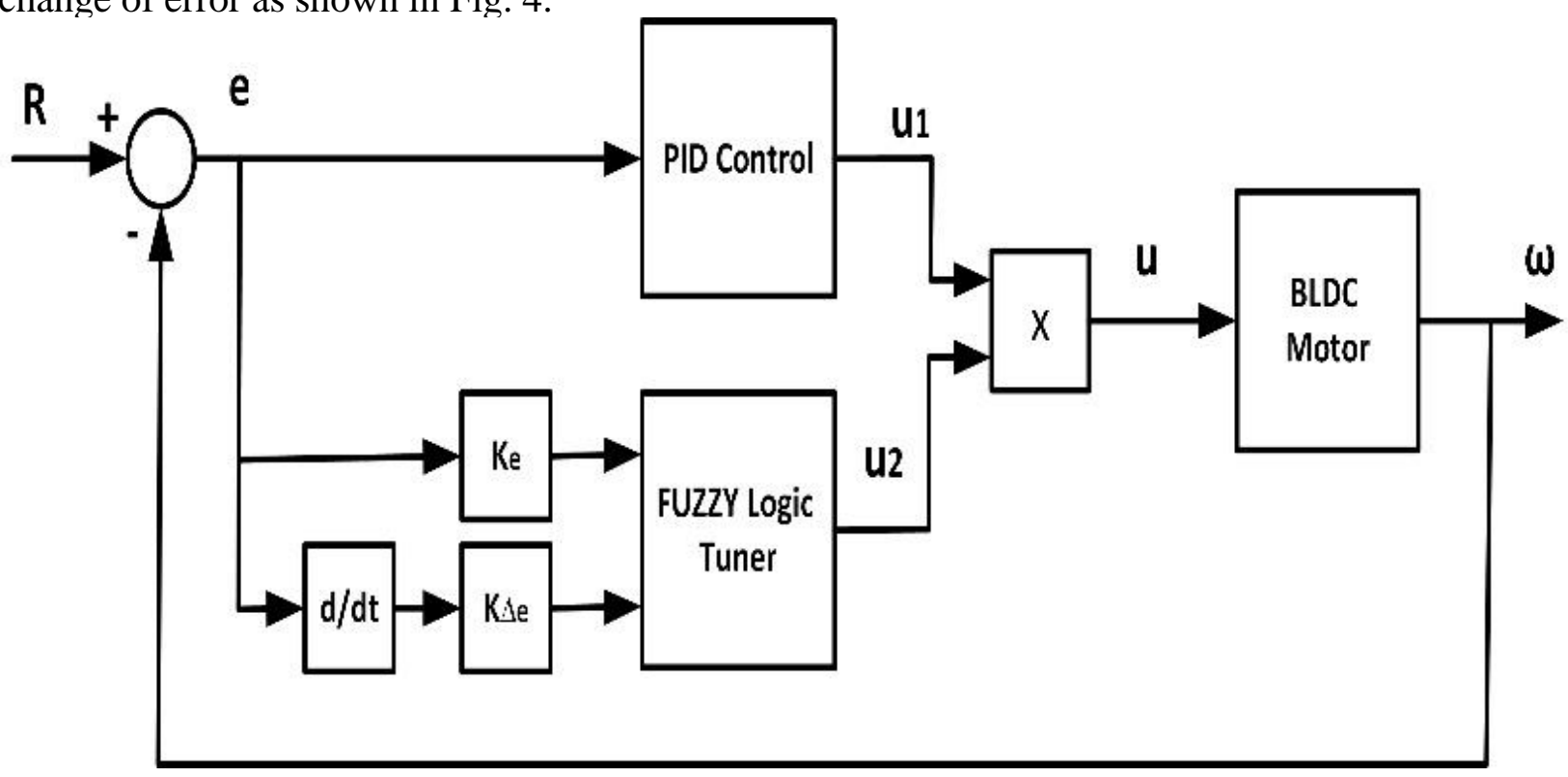

Fig. 4. Structure of self-tuning fuzzy PID control with BLDC motor.

Hence, the control action of self-tuning fuzzy PID control as following equations.

$$
\begin{gathered}
u=u_{1} * u_{2} \\
u_{1}=k_{p}+k_{i} \frac{1}{S}+k_{d} S \\
u=u_{2}\left[k_{p}+k_{i} \frac{1}{S}+k_{d} S\right]
\end{gathered}
$$

Where:

$u_{1}$ : The output of PID control.

$u_{2}$ : Fuzzy logic tuner output.

$u$ :The output of self-tuning fuzzy PID control.

The general structure of fuzzy logic control is represented in Fig. 5 and comprises three principal components. 


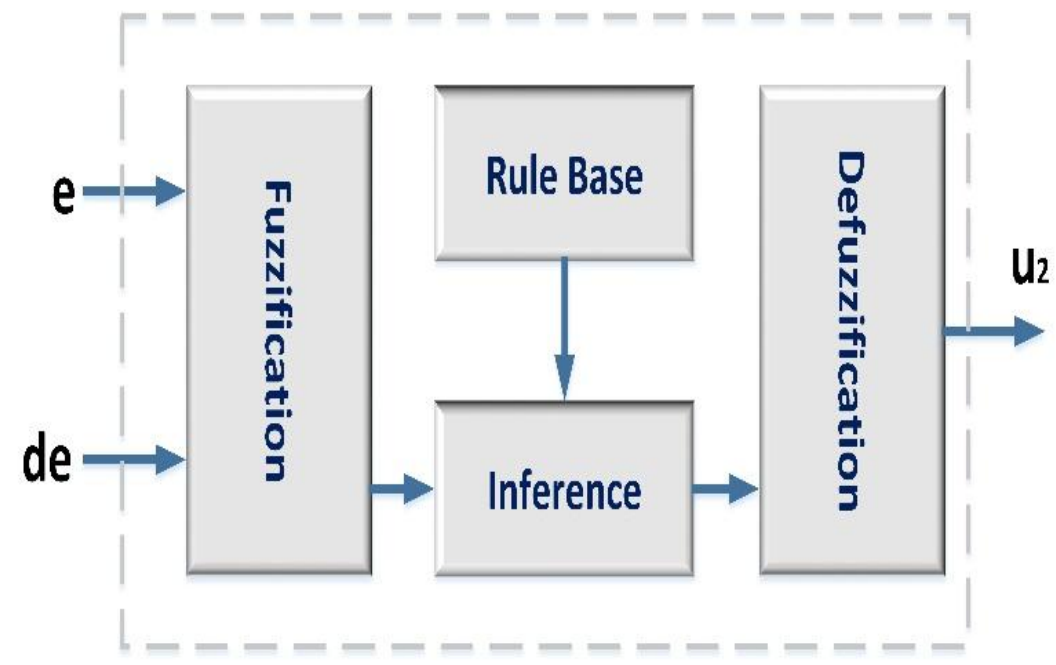

Fig. 5. Fuzzy logic control structure.

FLC has two inputs and one output. These are error (e), error change (de) and control signal, respectively. The linguistic labels used to describe the Fuzzy sets were; Negative Big (NB), Negative Medium (NM), Negative Small (NS), Zero (Z), Positive Small (PS), Positive Medium (PM), Positive Big (PB). The input and output membership functions is presented in Fig. 6 and Fig. 7 respectively.

It is possible to assign the set of decision rules as shown in Table I. The fuzzy rules are extracted from fundamental knowledge and human experience about the process. These rules contain the input/the output relationships that define the control strategy. Each control input has seven fuzzy sets so that there are at most 49 fuzzy rules.

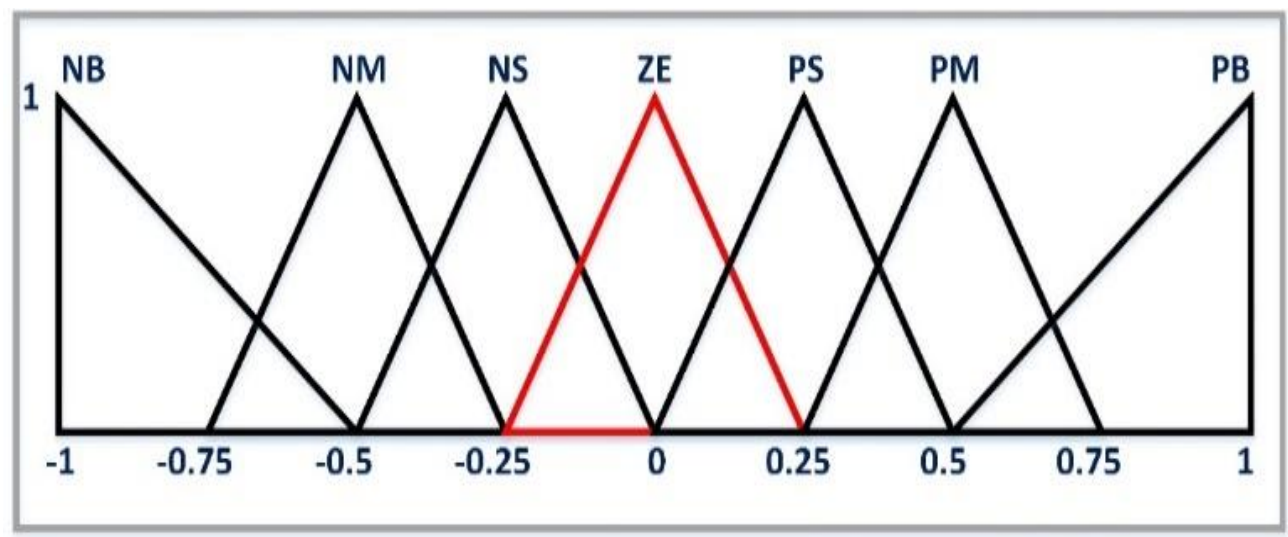

Fig. 6. Memberships function of inputs (e, $\Delta e)$.

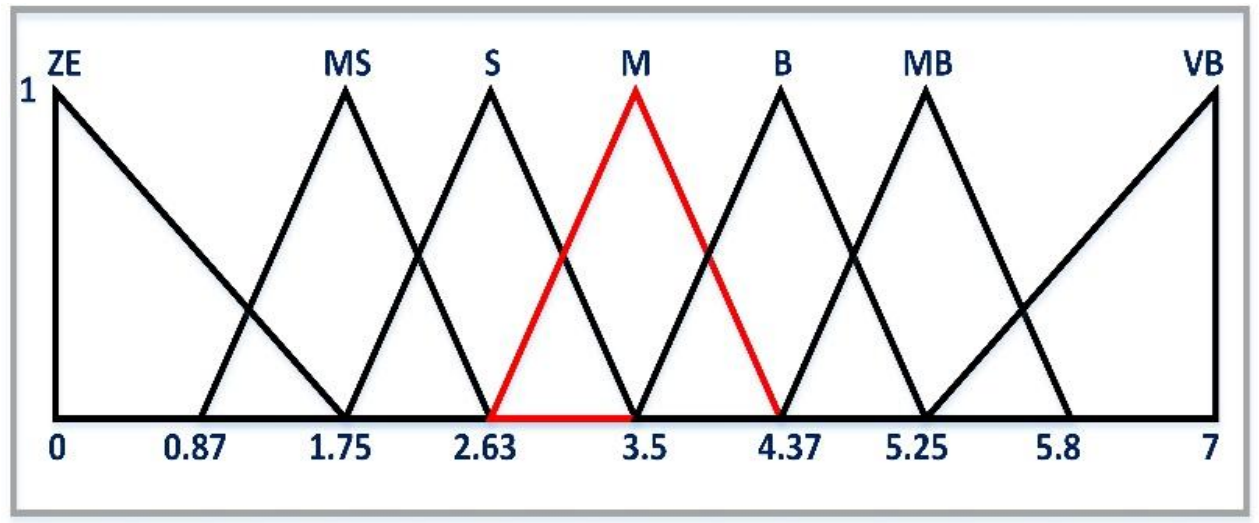

Fig. 7. Memberships functions of output $\left(u_{2}\right)$. 
TABLE II: FUZZY LOGIC RULE BASE

\begin{tabular}{|l|l|l|l|l|l|l|l|}
\hline $\begin{array}{c}\text { CE } \\
\text { E }\end{array}$ & NB & NM & NS & Z & PS & PM & PB \\
\hline NB & NB & NB & NB & NB & NM & NS & Z \\
\hline NM & NB & NB & NB & NM & NS & Z & PS \\
\hline NS & NB & NB & NM & NS & Z & PS & PM \\
\hline Z & NB & NM & NS & Z & PS & PM & PB \\
\hline PS & NM & NS & Z & PS & PM & PB & PB \\
\hline PM & NS & Z & PS & PM & PB & PB & PB \\
\hline PB & Z & PS & PM & PB & PB & PB & PB \\
\hline
\end{tabular}

\section{LABORATORY SETUP AND EXPERIMENTAL RESULTS}

\section{A. Laboratory Setup}

The experimental setup consists of four parts as shown in Fig. 8:

1) R2418 DC 12-24V Micro BLDC Motor Adjustable Speed + Brakes + Feedback Signal, $8700 \mathrm{rpm}$.

2) Power supply has input (220 V) and output (24 V)

3) Arduino Mega 2560 has the following specifications:

- 16 analog inputs, 4 UARTs (hardware serial ports), a $16 \mathrm{MHz}$ crystal oscillator,

- It has 54 digital input/output pins (of which 14 can be used as PWM outputs).

- USB connection, No extra power-supply needed.

4) Computer used to perform the control algorithms. Schematic.

Simulink Support Package for Arduino Hardware enables you to create and run Simulink® models on Arduino Mega 2560 board. The target includes a library of Simulink blocks for configuring and accessing Arduino sensors, actuators and communication interfaces. Complete set of tools for analog input, analog output, and digital I/O from a variety of PCcompatible data acquisition hardware. The toolbox lets you configure your external hardware devices, read data into MATLAB and Simulink environments for immediate analysis, and send out data. 


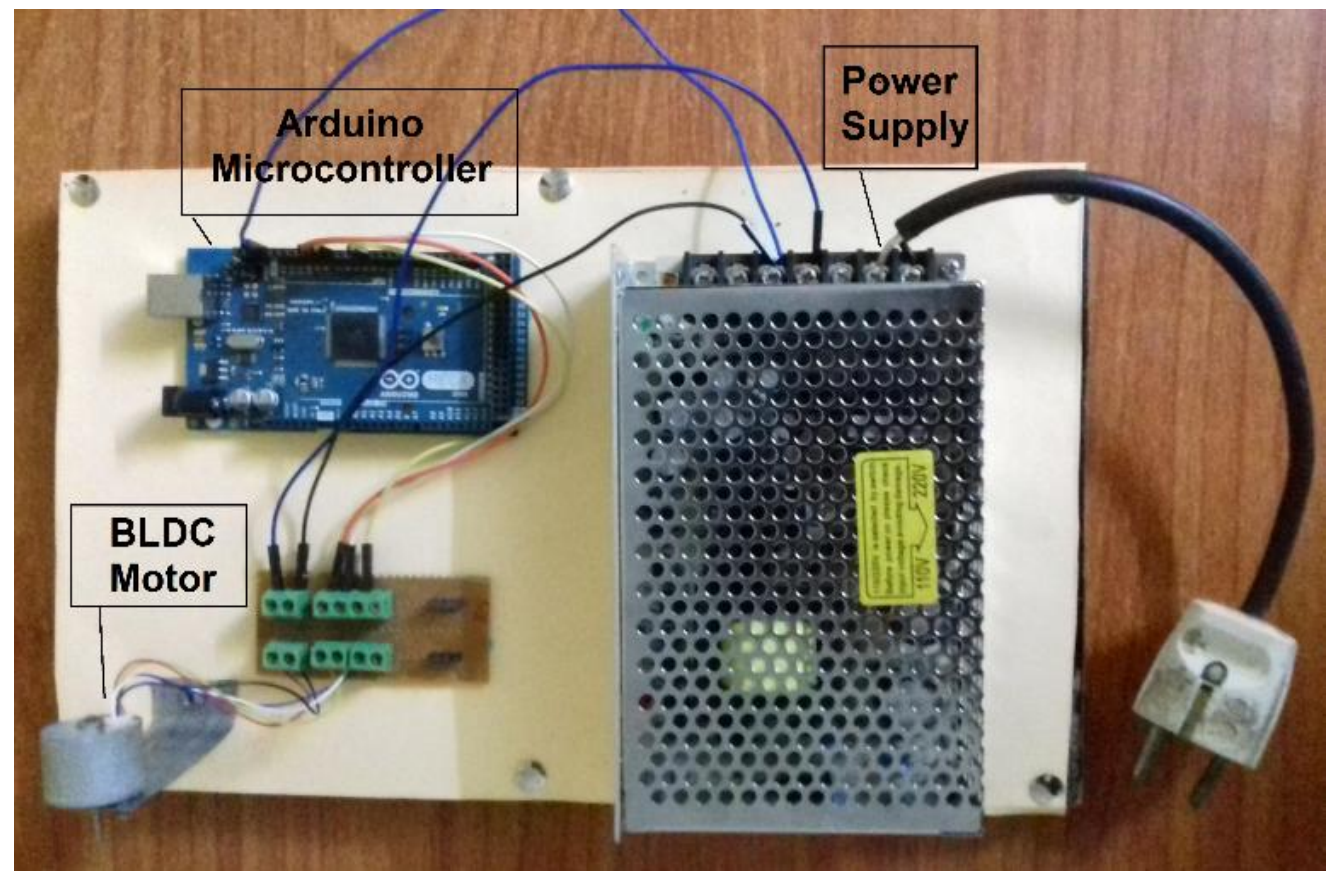

Fig. 8. BLDC motor experimental setup.

\section{A. Experimental Results}

This section shows the experimental results of PID control and self-tuning fuzzy PID control applied on BLDC motor drive system.

Fig. 9 demonstrates the speed response of BLDC motor drive system using PID control and self-tuning fuzzy PID control. It can be noted that the performance of self-tuning fuzzy PID control has faster response than other technique (minimum rise time and no overshoot).

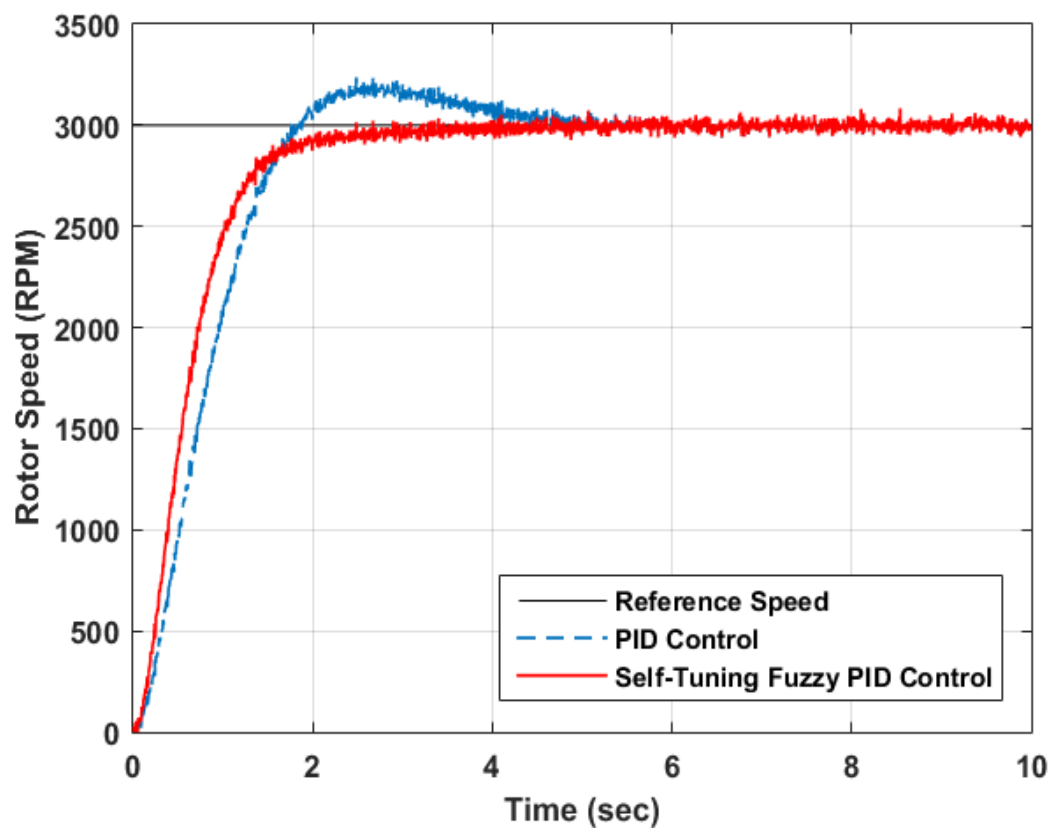

Fig. 9. Speed response of different types self-tuning PID control.

Fig.10 illustrates the corresponding controller output of each control technique. It can be noted that the self-tuning fuzzy PID controller output has a high value at starting of operation and reduce rapidly to reach the steady state value. 


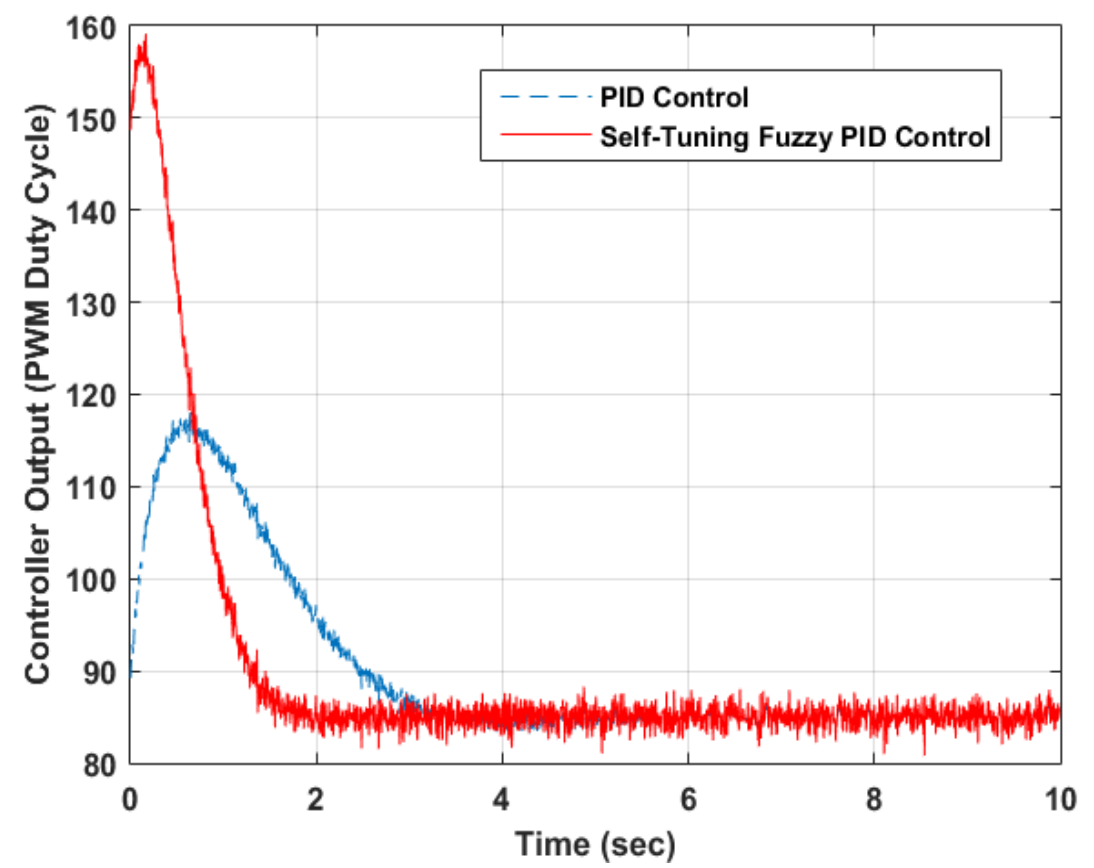

Fig. 10. Controller output of PID control and self-tuning fuzzy PID control.

Table III summarizes the performance of each control technique (PID control and selftuning fuzzy PID control).

Table Iii:COMPARISON BETWEEN CONTROL TECHNIQUES

\begin{tabular}{|c|c|c|c|}
\hline Controller Method & $\begin{array}{c}\text { Rise } \\
\text { Time(S) }\end{array}$ & $\begin{array}{c}\text { Settling } \\
\text { Time (S) }\end{array}$ & $\begin{array}{c}\text { Max. } \\
\text { Overshoot \% }\end{array}$ \\
\hline PID Control & 1.159 & 7.375 & 8.445 \\
\hline Self-Tuning Fuzzy PID Control & 1.031 & 5.375 & 3.114 \\
\hline
\end{tabular}

It clear that the second technique of self-tuning fuzzy PID control has minimum rise, settling time and acceptable overshoot compared with other technique.

Many of industrial applications the reference speed of BLDC motor is not constant and change continuously such as robotics and electric automotive. So, Fig.11 shows the PID control and self-tuning fuzzy PID control response at different commands of reference speed with constant. It can noted that the self-tuning fuzzy PID control can track the reference speed faster than other technique.

Fig.12 illustrates the corresponding controller output of each controller technique. It is obvious that the controller output of both two techniques increase at each sudden new reference speed command. 


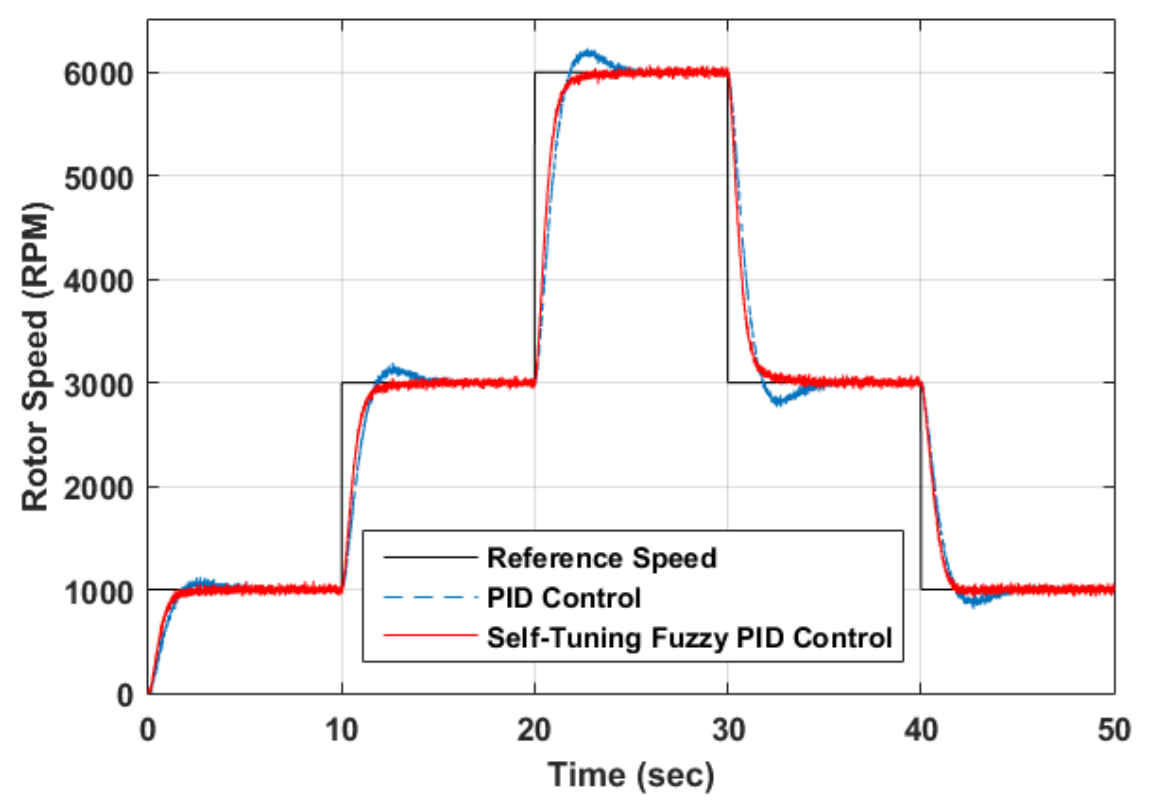

Fig. 11. Speed response of control techniques at different commands of reference speed

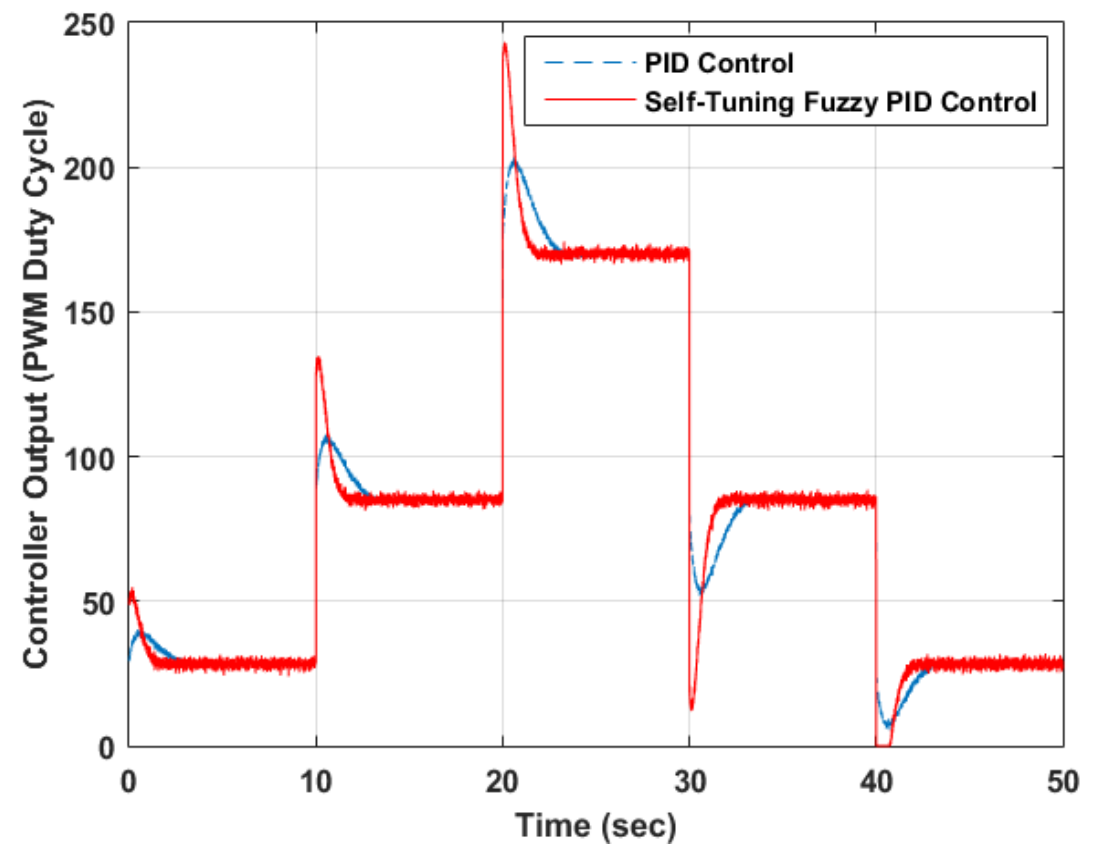

Fig. 12. Controller output of control techniques at different commands of reference speed.

\section{CONCLUSION}

This paper presents design and practical implementation of two different control techniques. The first technique is conventional PID control which its parameter obtained from Ziegler-Nichols. The second technique is the self-tuning fuzzy PID control where the PID control output was tuned according to error and change of error. The Arduino microcontroller is used as Data Acquisition Card to send and receive data from real system to computer. The experimental results illustrated that self-tuning fuzzy PID control has a good performance compared to conventional PID control. 


\section{REFERENCES}

[1] C.-L. Xia, Permanent Magnet Brushless DC Motor Drives and Controls. Singapore: John Wiley \& Sons Singapore Pte. Ltd., 2012.

[2] M. A. Shamseldin, M. A. Eissa, and A. A. El-samahy, "Practical Implementation of GA-Based PID Controller for Brushless DC Motor," in 17th International Middle East Power System Conference (MEPCON'15) Mansoura University,Egypt, December 15$17,2015,2015$.

[3] A. I. Technology, "THE DESIGN OF THE HYBRID PID-ANFIS CONTROLLER FOR SPEED CONTROL OF BRUSHLESS DC MOTOR," J. Theor. Appl. Inf. Technol., vol. 71, no. 3, pp. 367-376, 2015.

[4] A. A. El-samahy and M. A. Shamseldin, "Brushless DC motor tracking control using self-tuning fuzzy PID control and model reference adaptive control," Ain Shams Eng. J., 2016.

[5] V. Chopra, S. K. Singla, and L. Dewan, "Comparative Analysis of Tuning a PID Controller using Intelligent Methods," Acta Polytech. Hungarica, vol. 11, no. 8, pp. 235-249, 2014.

[6] M. A. Shamseldin and A. A. El-samahy, "Speed Control of BLDC Motor By Using PID Control and Self-tuning Fuzzy PID Controller," in 15th International Workshop on Research and Education in Mechatronics (REM), 2014.

[7] S. Sunisith, L. Joseph, and M. Saritha, "Comparison of Fuzzy PID Controller with Conventional PID Controller in Controlling the Speed of a Brushless DC Motor," Int. Electr. Eng. J., vol. 5, no. 12, pp. 1665-1672, 2014.

[8] M. R. Stankovi, M. B. Naumović, S. M. Manojlović, and S. T. Mitrović, "FUZZY MODEL REFERENCE ADAPTIVE CONTROL OF VELOCITY SERVO SYSTEM $\square$,"FACTA Univ. Ser. Electron. Energ., vol. 27, no. December, pp. 601-611, 2014.

[9] M. S. Sathyanarayana, "FUZZY IMPLEMENTATION OF MODEL REFERENCE ADAPTIVE CONTROL OF DC DRIVES,” IJESAT, vol. 2, no. 3, pp. 605-611, 2012.

[10] N. Tiwary, A. Rathinam, and S. Ajitha, "Design of Hybrid Fuzzy-PI controller for speed control of Brush less DC Motor," in International Conference on Electronics, Communication and Instrumentation (ICECI), 2014, pp. 1-4.

[11] G. Sakthivel, T. S. Anandhi, and S. P. Natarjan, "Real Time Implementation of DSP based Fuzzy Logic Controller for Speed Control of BLDC Motor," Int. J. Comput. Appl., vol. 10, no. 8, pp. 22-28, 2010.

[12] G. Prasad, N. S. Ramya, P. V. N. Prasad, and G. T. R. Das, "Modelling and Simulation Analysis of the Brushless DC Motor by using MATLAB," IJITEE, vol. 1, no. 5, pp. 27-31, 2012.

[13] N. Priyadarshi, "Real Time Modelling and Simulation of BLDC Motor," Int. J. Eng. Res. Technol., vol. 1, no. 6, pp. 1-6, 2012.

[14] A. P. C. Rao, Y. P. Obulesh, and C. S. Babu, "Mathematical modeling of bldc motor with closed loop speed control using pid controller under various loading conditions," ARPN J. Eng. Appl. Sci., vol. 7, no. 10, pp. 1321-1328, 2012. 